\title{
A INSERÇÃO DA MULHER INDÍGENA BRASILEIRA NA SOCIEDADEE CONTEMPORÂNEA ATRAVÉS DA LITERATURA
}

VERA LUCIA T. KAUSS ${ }^{1}$

UNIGRANRIO

ADREANA PERUZZO ${ }^{2}$

UNIGRANRIO

RESUMO: Desde a colonização, a mulher indígena brasileira passou a conviver com abusos e violências em vários níveis. Durante séculos, junto com seus povos, foram colocadas à margem da sociedade e obrigadas a continuar sofrendo, silenciadas, violências de toda espécie. Apenas no século XX, elas, através da literatura escrita, expressam suas dores e lutam pelos seus direitos.

PALAVRAS-CHAVE: Feminino; Indígenas; Literatura.

ABSTRACT: The Brazilian indigenous women have been undergoing abuse and violence in several degrees since the beginning of colonization. For centuries, along with their people, they have been pushed to the margins of society, forced to silently suffer all kinds of violence. It was only in the 20th century that they started to express their pain and to struggle for their rights through written literature.

KEYWORDS: Women; Indigenous; Literature.

Ao procuramos informações referentes à colonização europeia no território brasileiro, a história registra passagens bárbaras e grotescas no processo de colonização contra os povos que aqui habitavam. Todas as muitas e diferentes etnias que ocupavam o território foram denominadas, pelos europeus, de "índios"; vistos como seres inferiores

\footnotetext{
${ }^{1}$ Professora Doutora pela UFRJ em Literatura Comparada e professora do Mestrado e da Graduação da UNIGRANRIO - Universidade do Grande Rio. E-mail: verakauss @ globo.com .

${ }^{2}$ Pedagoga, Mestranda do Mestrado em Letras e Ciências Humanas da UNIGRANRIO - Universidade do Grande Rio. E-mail: pedagogaadreana@ bol.com.br .
}

Espaço Ameríndio, Porto Alegre, v. 6, n. 2, p. 32-45, jul./dez. 2012. 
VERA LUCIA KAUSS e ADREANA PERUZZO - A inserção da mulher indígena brasileira...

pelos parâmetros científicos da época, que consideravam os europeus como uma raça superior e "civilizada". Podemos fazer uma observação dessa leitura partindo do que nos diz Julia Falivene Alves:

No entanto, a história de nosso país foi sempre analisada apenas do ponto de vista do dominador. Por isso, encaramos a chegada, conquista e dominação europeia na América como "mais uma etapa gloriosa de uma civilização superior", cumprindo seu destino inexorável de espalhar pelo mundo as verdades engendradas durante 0 seu específico e particular processo de desenvolvimento histórico (ALVES, 2004, p. 25-26).

Para que os espaços indígenas fossem colonizados, ocorreram invasões que massacraram e destruíram suas moradias e suas plantações. Milhares de índios foram mortos à espada, com armas de fogo e, outros milhares, por causa de viroses, muitas vezes, intencionalmente disseminadas. Como se isso não bastasse, outros tantos foram escravizados e também mortos, pois não se rendiam às cruéis imposições dos segmentos "brancos", que queriam obrigá-los a abandonar a cosmovisão que, até então, regia suas vidas enquanto seres individuais e coletivos. Tal resistência lhes rendeu estereótipos, como: selvagens, primitivos, preguiçosos, bestiais, monteses, enfim, eram vistos como seres não racionais, sem alma e sem fé. Porém o Papa Paulo III, em 1537, expediu uma bula Papal, Sublimis Deus, que afirmava que os indígenas eram homens e não bestas, possuidores de alma e dignos de conversão. A bula Sublimis Deus foi considerada pelos jesuítas a primeira declaração universal dos direitos humanos.

Hoje em dia, também através de textos literários, os povos indígenas procuram resgatar sua imagem e elucidar as muitas ideias preconceituosas disseminadas sobre eles. É o que podemos observar nessa passagem de Daniel Munduruku, da etnia Munduruku, em que ele tenta mostrar a diferença de cosmovisão dos que aqui viviam e vivem em relação aos que chegaram depois, em relação, por exemplo, à ideia de tempo e trabalho:

Tempo e trabalho não são sinônimos. Trabalho e dinheiro também não. Trabalho não dignifica se ele escraviza. Trabalho demais nos dá tempo de menos. $\mathrm{E}$ tempo de menos nos tira a alegria do encontro com os 
VERA LUCIA KAUSS e ADREANA PERUZZO - A inserção da mulher indígena brasileira...

pais, com os filhos, com os amigos. Só o presente é um presente. O futuro é uma promessa que pode nunca chegar. Os indígenas sabem disso (MUNDURUKU, 2009, p. 50).

A tentativa europeia de dominação dos povos indígenas não rendeu os resultados esperados, por isso atribuíram aos indígenas o estereótipo de que "índio é preguiçoso" (MUNDURUKU, 2009, p. 49). Os índios não se tornavam servis, portanto não eram bons escravos. Gilberto Freire registra que "a enxada nunca se firmou na mão do índio nem na do mameluco; nem seu pé de nômade se transformou em péde-boi paciente e sólido" (FREIRE, 1999, p. 95). Mesmo com a resistência, milhares de indígenas foram escravizados, durante a colonização brasileira, pelos portugueses, que se utilizaram de armas de fogo, entre outros subterfúgios, para conseguir o domínio e a obediência dos indígenas escravizados.

Nesse período, a escravidão dos chamados "negros da terra" foi utilizada para o trabalho do cultivo da cana-de-açúcar, coleta de frutos e sementes nativos, como o cacau, a baunilha, o cravo, a castanha-dopará e, também, da extração da madeira. Freire (1999, p. 95) aponta que, durante o processo de colonização e da escravidão, a maior contribuição indígena à agricultura foi a "coivara", que é uma espécie de preparação do solo através da queimada dos vegetais para o cultivo das plantações.

Os indígenas viviam em comunidades em que a terra não era apenas de um, mas de todos os que nela habitavam, não faziam demarcações territoriais e nem comercializavam os produtos que cultivavam. Tudo era organizado entre todos os membros da tribo, inclusive as tarefas do dia-a-dia eram divididas por idade e por gênero: os homens tinham suas funções, e as mulheres, as delas. A atribuição de tarefas específicas não significava inferioridade ou distinção de poder, eram, simplesmente, tarefas que precisavam ser feitas para o bem de todos.

Como se a escravidão imposta pelos colonizadores não bastasse, os primeiros habitantes brasileiros sofreram também com a invasão cultural. A história nos mostra que o conhecimento e os ensinamentos indígenas, como a dança, o canto, a evocação dos espíritos, as histórias 
VERA LUCIA KAUSS e ADREANA PERUZZO - A inserção da mulher indígena brasileira...

e o poder curativo das ervas eram repassados de geração a geração e, mesmo com o passar do tempo, o conhecimento e os ensinamentos não se perdiam nem se esvaziavam, perpetuavam-se vivos em cada indígena da tribo.

Porém, com a chegada dos padres jesuítas, houve uma intensa catequização das crianças, com a intenção de levá-las a aprender a obediência a um Deus todo poderoso, católico e, com isso, incitando-as a abandonar sua tradição étnica e linguística. $O$ cristianismo apresentado pelos padres validava o que fora dito pelos europeus desde que aqui chegaram: que os indígenas eram grotescos e precisavam ser educados, civilizados. Com o Deus Cristão, ficariam libertos dos temerosos demônios e dos comportamentos bárbaros.

No texto Eva Tupinambá, de Ronald Raminelli (2009, p. 11), o autor nos diz que "a cultura indígena foi descrita a partir do paradigma teológico e do princípio de que os brancos eram os eleitos de Deus", portanto, de fato, não havia nenhuma possibilidade de uma relação de gentileza entre as etnias brasileiras e europeias: os de lá eram civilizados e os de cá eram selvagens. Pelo menos era o que eles diziam.

Em virtude da mortalidade dos povos indígenas durante as invasões, muitas crianças ficaram órfãs, muitas mulheres se tornaram viúvas e muita sabedoria foi ceifada com a morte dos anciãos. Para o indígena, o respeito que se dá aos que tem mais idade é algo vital e de grande relevância, pois eles simbolizam a sabedoria ancestral e a sua memória, que tem a função de preservar informações ancestrais e possibilitar a manutenção da identidade indígena. Igualmente, respeitam as crianças e as mulheres, sendo que estas eram consideradas mais próximas da mãe terra, ou seja, muito preciosas por terem o dom de gerar a vida em si, perpetuando, assim, seu povo. 0 guia de pesquisa Coisas de Índio, do professor e escritor Daniel Munduruku (2000, p. 48), nos diz que "As crianças ocupam um espaço privilegiado na sociedade indígena. Desde o momento que nascem, são tratadas de forma muito carinhosa".

As mulheres indígenas, em nossos dias, estão tomando também posse da escrita para, elas mesmas, mostrarem o sofrimento da violência e da marginalização a que foram relegadas desde a construção dessa sociedade não indígena que começou com a colonização e que 
VERA LUCIA KAUSS e ADREANA PERUZZO - A inserção da mulher indígena brasileira...

continua até nossos dias. A literatura, para essas mulheres, também é mais um instrumento de luta pelo lugar a que têm direito numa sociedade que as marginalizou desde sua formação. E é um pouco desse grito de revolta e de dor que podemos encontrar em seus poemas ou textos narrativos. É o que podemos perceber neste trecho de um belo poema de Eliane Potiguara que diz:

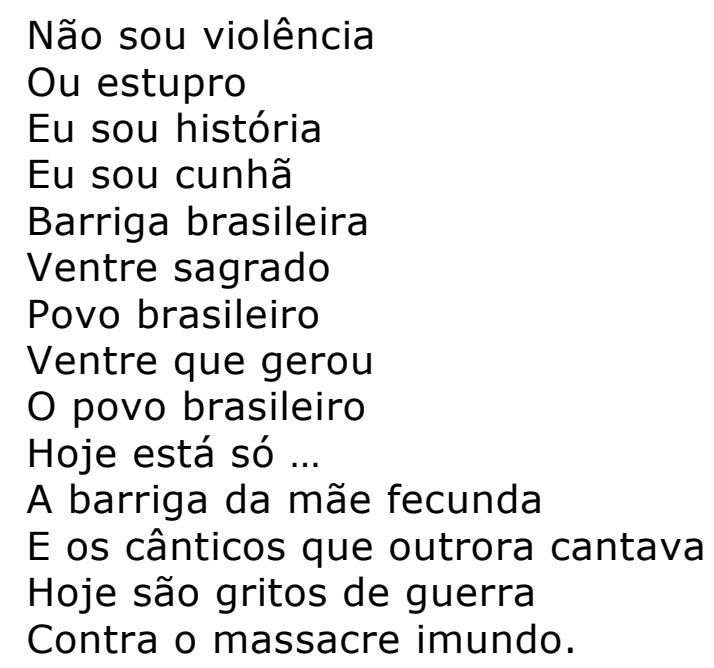

(POTIGUARA, 2004, p. 34-35).

A nudez da mulher indígena causava admiração nos europeus, e eles as comparavam com as das mulheres que haviam deixado na Europa: consideravam que as índias eram muito mais bonitas do que as mulheres europeias. Em sua famosa carta, Caminha descreve a genitália feminina indígena dizendo que: "sua vergonha (é) tão graciosa, que a muitas mulheres de nossa terra, vendo-Ihe tais feições, fizera vergonha, por não terem a sua como ela", como nos diz Manuela Carneiro da Cunha (CUNHA, 1993, p. 155).

Para o indígena, o sexo faz parte de sua natureza. A nudez entre todos os membros da tribo não era uma forma de representar a sensualidade ou a sexualidade, nem mesmo de causar provocações ao sexo oposto. Para os povos indígenas, andar nu fazia parte de seu cotidiano e suas convenções sociais ratificavam esse costume, ao contrário do que acontecia na Europa, recém saída da Idade Média, que condenava o corpo humano como pecaminoso, caminho para a lascívia, para a luxúria e para o inferno. Lá, as mulheres precisavam cobrir totalmente seu corpo, não podiam se deixar olhar porque, baseada em um pensamento misógino, principalmente a Igreja, que era quem ditava 
VERA LUCIA KAUSS e ADREANA PERUZZO - A inserção da mulher indígena brasileira...

o bom proceder moral, via no corpo feminino uma via de transgressões que levava invariavelmente à senda do pecado e do inferno.

Ao falarmos do universo feminino brasileiro, nos vem à memória a mulher branca, a mulata e a negra. Mesmo com esforço, muito improvavelmente, virá à memória a mulher indígena, isso, possivelmente, se deve à invisibilidade que foi atribuída aos povos indígenas no Brasil.

$\mathrm{Na}$ nossa sociedade, ocorreu uma grande evolução e, com ela, surgiram, por exemplo, inúmeras invenções através de avanços tecnológicos importantes. Apesar desse desenvolvimento no lado tecnológico de nossa sociedade, nada foi feito para retirar o véu de invisibilidade imputada, entre outros indivíduos, às mulheres indígenas. Uma forma de observarmos esse fato é procurar textos literários que se refiram a elas: os poucos textos encontrados não as colocam como personagens principais e, quando o fazem, elas aparecem idealizadas ou em papéis carregados de sentido pejorativo.

Em nossos dias, são as próprias mulheres indígenas que tomam a palavra em sua defesa e o fazem literalmente, pois apossaram-se da escrita em nível acadêmico. Elas estão colocando no papel o que até então ficava somente na oralidade e, dessa forma, estão tornando-se visíveis para a sociedade contemporânea.

Observa-se que, na era contemporânea, as mulheres indígenas assumem o papel de líderes para defenderem e adquirirem direitos para seu povo. Lutam para que políticas públicas sejam instituídas para que, através delas, possam reivindicar, por exemplo, a demarcação das terras que, ancestralmente, pertencem a seus povos; leis que as defendam da violência física, como os abusos sexuais; da exploração da mão de obra; lutam para conseguir saúde e escolas para as crianças; enfim, que lhes sejam devolvidos o respeito e a dignidade, além do lugar que lhes foi usurpado desde a colonização na sociedade brasileira que ajudaram a construir.

Em seus textos literários, divulgados em diversas mídias, expressam sua cultura, reverenciam seus antepassados, dão a conhecer seus costumes, mostram suas dores, seus temores, sua memória e, principalmente, apresentam muito zelo em deixar acesa a luz de sua 
VERA LUCIA KAUSS e ADREANA PERUZZO - A inserção da mulher indígena brasileira...

identidade. É ainda Eliane Potiguara (2004, p. 87) que, com um dos seus poemas, exemplifica o que dissemos:

[...] Faço agora um acordo entre meu ego e minha alma.

Minha alma é primeira, é forte, é intuitiva, eterna amante, indígena.

Mas meu ego, condicionado pela cultura dominante, me leva para a escuridão terrena, celestial, marítima, onírica e filosófica.

Conduz minha autoestima para os porões.

Não, mulheres do mundo!

Não aceitemos mais!

$[\ldots]$

Meu ego não pode ser mais forte do que minha alma, minha anima, minha essência de mulher selvagem, indígena, essencial à preservação digna do planeta e dos seres humanos.

Basta de violência.

Nós somos lobas.

Somos músicas que ecoam no etéreo.

Nós somos foca.

Nós somos Humanidade e sabemos o que é digno para nós.

Nossa pele de foca brilha de novo.

Ouçamos definitivamente nossas velhas e velhos.

(POTIGUARA, 2004, p. 87).

Podemos observar muitos estereótipos registrados em obras literárias produzidas pelos autores não indígenas e, neles, encontramse referências de que não há beleza na mulher indígena ou ainda, como fez o escritor romântico José de Alencar (2011) em Iracema, considerada uma das principais obras do Indianismo brasileiro. Nesse romance, mesmo com as descrições que o autor faz de Iracema, identificando-a com as exuberantes belezas naturais, não consegue fugir da representação feminina de sua realidade, descrevendo-a como "mulher e esposa ideal", suportando "sem revolta o desprezo do esposo" (CAVALCANTI, 2002, p. 19).

Ao lermos Iracema, de José de Alencar (2011), vemos que o romance nos mostra uma índia da tribo tabajara, chamada Iracema, que vive um grande amor com um dos colonizadores portugueses do Ceará, de nome Martim. No texto, o escritor representou, na união desse casal por amor, um símbolo do encontro de dois povos com consequências trágicas para os indígenas. O casal teve um filho, chamado Moacir, que significa "filho da dor", que era o representante de uma nova etnia que se formava no Brasil: os brasileiros. 
VERA LUCIA KAUSS e ADREANA PERUZZO - A inserção da mulher indígena brasileira...

Martim era amigo da nação potiguara, que habitava o litoral cearense. As duas nações indígenas, tabajara e potiguara, eram inimigas, havia ódio e rixas entre ambas, e uma grande batalha acontece entre os dois povos.

Com o sofrimento e morte do seu povo, com o desprezo e com a ausência de seu amado, Iracema é invadida por amarguras e tristezas que a levam à morte. Martim parte do local levando com ele o filho nascido da mistura das duas etnias, e que representa, para muitos, o primeiro brasileiro. Essa morte simboliza a força, o poder e a ascensão dos colonizadores portugueses e sua cultura sobre os povos indígenas que habitavam Pindorama.

No entanto, no universo indígena, a mulher ocupava um espaço definido e muito valioso nas decisões familiares. As vozes indígenas feminina e masculina decidiam juntas, inexistia a representação do domínio e do poder do gênero masculino, cada qual tinha seu espaço de atuação e não se questionavam esses lugares colocados pela tradição. É ainda no livro de Eliane Potiguara que buscamos o apoio de seu testemunho sobre a relação entre homem e mulher e as mudanças que ela sofreu desde a colonização:

Ao longo da história, o homem indígena teve de mudar seu comportamento com a mulher indígena, numa tentativa desesperada e inconsciente de preservar a família. No período das colonizações portuguesa e espanhola, no Brasil, os homens indígenas conduziam toda a sua família ao suicídio coletivo, contra a escravidão, e, consequentemente, à destruição cultural. Nos tempos atuais, o suicídio, a submissão, o alcoolismo, a desesperança, a fome tem sido sintomas da opressão colonizadora, decorrentes da violência dos direitos humanos fundamentais dos povos indígenas e que afetam as mulheres mais diretamente (POTIGUARA, 2004, p. 82).

A hegemonia do masculino em relação ao feminino era comum na cultura europeia e reafirmada sempre pelo cristianismo, que usava passagens bíblicas para manutenção do poder masculino. Como nos diz Raminelli (2009, p. 42): "No final do século XVI, vários teólogos reafirmaram que o sexo oposto era mais frágil em face das tentações por estar repleto de paixões vorazes e veementes". 
VERA LUCIA KAUSS e ADREANA PERUZZO - A inserção da mulher indígena brasileira...

Dizer que a literatura é catarse, ou elemento de purificação apenas, é reduzi-la a conceitos demais limitados. A literatura é uma grande metáfora da vida do homem. Sendo assim, é sempre surpreendentemente, uma maneira nova de se apreender a existência e instituir novos universos (CAVALCANTI, 2002, p. 12).

Uma observação sobre o que é literatura para os indígenas merece atenção, pois, para eles, a literatura não depende do registro pela escrita. Para o indígena, tudo é literatura, tudo em si se faz literatura. Quando os indígenas expressam as mais variadas formas de suas crenças, suas danças e seus costumes, como, por exemplo, colorir o corpo; quando entoam suas canções, quando contam suas histórias, quando interagem com a natureza, quando fazem rituais de cura, estão produzindo literatura, estão vivendo a literatura.

As letras que transformam a literatura indígena em signos e a redigem, registrando em papéis ou outras formas de serem levadas e vistas pelo mundo além do horizonte das culturas indígenas, tornam as mulheres mais presentes e atuantes na busca por denunciar os maus tratos por que passam, como: abusos sexuais, desprezos, humilhações e tantas outras violências que sofrem até hoje. A literatura é um instrumento que leva a lugares além de seus espaços originais as reivindicações que as mulheres indígenas fazem em defesa de todos os membros de seu povo. Como nos diz Daniel Munduruku:

Compreender a Literatura Indígena é entender que ela se manifesta nas diversas formas de transmissão do saber: que ela é a reverberação do que mora dentro do corpo de nossa gente. A literatura entendida nesses moldes - nos completa enquanto pessoas, porque nos lembra sempre de onde viemos, para onde vamos e qual o sentido de nossa pertença a esse planeta. É, portanto, um modo todo peculiar de ler o mundo em que vivemos e dar uma criativa resposta às questões que a vida está sempre nos levantando. É assim que entendemos essa forma peculiar de ler o mundo que o ocidente decidiu batizar de literatura. É assim que a temos reelaborado e compreendido que é, também uma forma de atualizarmos a memória responsável pela manutenção da nossa história (MUNDURUKU, 2005, p. 9-10). 
VERA LUCIA KAUSS e ADREANA PERUZZO - A inserção da mulher indígena brasileira...

A compreensão de literatura para o povo indígena difere da maneira de pensar e fazer literatura dos não indígenas, porque eles não têm necessidade da apresentação sob a forma da escrita, pois, como vimos acima, os indígenas consideram literatura toda forma de expressão. A leitura que fazem é visceral, usam seus sentidos, sua potencialidade sensível para entrar em sintonia literária e respirá-la pelos poros de toda a pele que reveste o corpo, não apenas por apenas um órgão dos sentidos.

Viver e reviver a sabedoria ancestral é a literatura em que se pode ver a construção e a luta pela manutenção da identidade indígena, e isso dá sentido à existência desses povos. É algo que leva ao conhecimento de que a vida deve ter como companheira a vida do outro, que os faz viver sua diversidade dentro do universo cultural em que se inserem, dentro da sua verdadeira cosmovisão, aceitando a diferença não como algo pejorativo ou inferior, mas simplesmente como não igual, não semelhante.

As expressões de vida dos indígenas, como dançar, cantar, pintar o corpo e tantas outras, não se limitam a palavras escritas, ultrapassam essas fronteiras. Para serem compreendidas pelos não indígenas, porém, elas precisam que estes respondam com sensibilidade, transponham a barreira do preconceito e procurem entender 0 significado que esses gestos possuem e qual a mensagem que estão transmitindo. Essa compreensão do mundo foi sendo repassada de geração a geração, através da oralidade, sustentando a harmonia entre os indígenas de cada etnia.

Antes dos contatos entre indígenas e não indígenas, alguns povos nativos utilizavam-se das pinturas rupestres para expressar "suas aventuras, seus mitos, suas histórias" e deixá-los registrados para seus descendentes e demais membros do seu povo. Da oralidade, após um tempo cronológico bastante longo quando nos referimos ao Brasil, depois de muitos séculos de resistência, partiram para o domínio das letras, aprendidas com os não indígenas, sendo que "essa passagem ocorreu por honra e graça de suas almas, que assim os convenceram a se manifestar" (SILVA, 2005, p. 8). Essa manifestação Ihes possibilita se 
VERA LUCIA KAUSS e ADREANA PERUZZO - A inserção da mulher indígena brasileira...

expressarem via escrita e mostrarem-se por um outro meio ao mundo que Ihes nega visibilidade.

Esse expressar-se nas diversas formas literárias não faz com que neguem sua identidade, como vemos em uma das partes do poema "Canção Peregrina", de autoria de Graça Graúna, que se encontra na Antologia Indígena:
As pedras do meu colar são história e memória Do fluxo do espírito
De montanhas e riachos
De lagos e cordilheiras
De irmãos e irmãs
Nos desertos da cidade
Ou no seio das florestas

(GRAÚNA, 2005, p. 27).

As mulheres indígenas procuram adaptar-se ao mundo contemporâneo e, através de seus textos literários, vão abrindo espaços e conquistando um lugar que é seu na sociedade brasileira. No entanto, sua origem e a cosmogonia que trazem em si continuam gravadas na memória e não são destruídas e nem se corrompem com o contato com outras maneiras de viver e de pensar o mundo com que passam a conviver no cotidiano contemporâneo das cidades, longe de suas origens. Através da memória preservada, acontece a retomada dos mitos e tradições para que se lembrem sempre de sua etnia, dos seus antepassados e de tudo o que aprenderam com seu povo.

No Brasil, temos, entre outras, duas figuras femininas que se destacam na literatura por divulgar as condições de vida das mulheres indígenas: Graça Graúna e Eliane Potiguara. Eliane é conhecida nacional e internacionalmente com seu trabalho de defesa dos povos indígenas. Foi a primeira escritora nativa que conseguiu, com seu poema "Identidade Indígena", na década de 70, ganhar publicação de abrangência nacional e "driblar a censura e o regime militar" (POTIGUARA, 2004, p. 18). Vejamos um fragmento do poema:

\footnotetext{
Nosso ancestral dizia: temos vida longa Mas caio da vida e da morte E range o armamento contra nós
} 
VERA LUCIA KAUSS e ADREANA PERUZZO - A inserção da mulher indígena brasileira...

Mas enquanto eu tiver o coração aceso

Não morre a indígena em mim

E nem tampouco os compromissos que assumi

Perante os mortos

De caminhar com minha gente passo a passo

E firme em direção ao sol [...]

(POTIGUARA, 2004, p. 102).

A autora do poema retrata o poder e a força dos não indígenas, que, se utilizando de armamentos, poder político, econômico e força bruta contra os povos indígenas, tiraram-Ihes a garantia de viver suas próprias histórias, impondo novos costumes e crenças. Potiguara não aceita a morte da identidade indígena e permanecerá lutando pelo seu povo enquanto tiver vida.

Do âmago da mulher indígena, por causa do desrespeito aos povos nativos, surge uma fera selvática - sua verdadeira identidade empossada de coragem para defender e erguer-se em defesa de seu povo diminuído, que está num "novo mundo" convivendo com doenças, desamparos, estereótipos e explorações das mais deploráveis, como o alcoolismo, as loucuras. Tudo isso desde o século XVI até os dias de hoje, século XXI.

Para sair do anonimato, mostrar-se como um ser de valor, emergir no mundo contemporâneo e dissolver os estereótipos, é necessário movimento. A literatura foi um dos alicerces para a impulsão da luta da mulher indígena. Para fortalecer essa luta feminina indígena, entre outras ações afirmativas, surgiu o GRUMIN, uma Rede de Comunicação Indígena. Foi criado no ano de 1987 e tem como finalidade promover o acesso de mulheres e homens indígenas ao exercício da cidadania. Através dessa entidade, luta-se pela efetiva construção de políticas públicas voltadas para a proteção das mulheres indígenas em relação aos problemas e preconceitos que enfrentam em sua luta cotidiana por um lugar - a que tem direito - na sociedade brasileira.

Observa-se com certa facilidade que a literatura é um dos principais instrumentos culturais de inserção social para uma minoria, independente de etnia ou classe social, econômica ou política. Através dela, a voz pode ser representada em signos para a divulgação do conhecimento.

Espaço Ameríndio, Porto Alegre, v. 6, n. 2, p. 32-45, jul./dez. 2012. 
VERA LUCIA KAUSS e ADREANA PERUZZO - A inserção da mulher indígena brasileira...

No universo indígena, os precursores a se inserirem no mundo dos não indígenas a partir da literatura foram os homens, em seguida, as mulheres, porém ambos escrevem e lutam pelo direito de reconhecimento de seus povos em todos os sentidos.

Percebe-se que, entre os gêneros literários, o poético é muito utilizado, tanto pelo homem como pela mulher indígena. É nas letras que os sentimentos e todo o universo dos indígenas são expressos sem medo e sem retalhamento.

Relatos de discriminações étnicas, de preconceitos, de explorações, de perdas, de mortes, de nostalgias, de enfrentamentos, de batalhas, de conquistas, de massacres; enfim, a memória, a história, a identidade, a cultura, a luta pela dissolução dos estereótipos que Ihes foram agregados ao longo do processo de "civilização" que sofreram e, além disso, a luta pela manutenção da identidade indígena são registros que já estão saindo da oralidade e se transformando em códigos registrados em vários gêneros literários. Como diz Eliane Potiguara:

Bonito é florir no meio dos ensinamentos impostos pelo poder. Bonito é florir no meio do ódio, da inveja, da mentira ou do lixo da sociedade. Bonito é sorrir ou amar quando uma cachoeira de lágrimas nos cobre a alma! Bonito é poder dizer sim e avançar. Bonito é construir e abrir portas a partir do nada. Bonito é renascer todos os dias. Um futuro digno espera os povos indígenas de todo o mundo (POTIGUARA, 2004, p. 79).

Enfim, as letras possibilitaram às mulheres indígenas um caminho para sair do anonimato, retirar o véu que as cobria e passar a serem vistas pela sociedade não indígena. Seus textos, poesias, romances; enfim, tudo o que escrevem são verdadeiros legados do universo feminino indígena a seus povos, são bandeiras de luta que essas guerreiras continuam levantando, carregando e fincando nessa sociedade que as discrimina duplamente: como mulheres e como indígenas que não se envergonham de sua origem, que continuam lutando por um espaço de respeito e reconhecimento, não apenas por seu valor individual, mas dos seus povos enquanto primeiros habitantes dessa nossa terra, o Brasil. 
VERA LUCIA KAUSS e ADREANA PERUZZO - A inserção da mulher indígena brasileira...

\section{Referências bibliográficas}

ALENCAR, José de. Iracema. São Paulo: Moderna, 2011.

ALVES, Júlia Falivene. A invasão cultural norte-americana. São Paulo: Moderna, 2004.

CAVALCANTI, Joana. Caminhos da literatura infantil e juvenil: dinâmicas e vivências na ação. São Paulo: Paulus, 2002.

CUNHA, Manuela Carneiro da. Histórias dos Índios no Brasil. São Paulo: Companhia das Letras, 1993.

FREIRE. Gilberto. Casa-Grande e Senzala. Rio de Janeiro: Record, 1999.

GRAÚNA, Graça. Canção Peregrina. In: Antologia Indígena. Mato Grosso: INBRAPI, 2005. p. 27-28.

MUNDURUKU, Daniel. Coisas de índio. São Paulo: Callis, 2000.

Literatura que se faz com os ritos e palavras. In: Antologia Indígena. Mato Grasso: INBRAPI, 2005. p. 9-10.

Sobre tempo e trabalho. In: Antologia Indígena. Mato Grosso: INBRAPI, 2009. p. 49-50.

POTIGUARA, Eliane. Metade Cara, Metade Máscara. São Paulo: Global, 2004.

RAMINELLI, Ronald. Eva Tupinambá. In: DEL PRIORE, Mary (Org.). História das Mulheres no Brasil. São Paulo: Contexto, 2009. p. 11-44.

SILVA, Paulo Pitaluga Costa e. A alma do índio. In: Antologia Indígena. Mato Grosso: INBRAPI, 2005. p. 8-11. 